\title{
In vitro effects of imatinib mesylate on radiosensitivity and chemosensitivity of breast cancer cells
}

\author{
Marion T Weigel ${ }^{1}$, Linda Dahmke ${ }^{1}$, Christian Schem ${ }^{1}$, Dirk O Bauerschlag ${ }^{1,2}$, Katrin Weber ${ }^{1}$, Peter Niehoff ${ }^{3}$, \\ Maret Bauer', Alexander Strauss', Walter Jonat', Nicolai Maass ${ }^{1,2}$, Christoph Mundhenke ${ }^{1 *}$
}

\begin{abstract}
Background: Breast cancer treatment is based on a combination of adjuvant chemotherapy followed by radiotherapy effecting intracellular signal transduction. With the tyrosine kinase inhibitors new targeted drugs are available. Imatinib mesylate is a selective inhibitor of bcr-abl, PRGFR alpha, beta and c-kit. The purpose of this study was to determine whether Imatinib has an influence on the effectiveness of radiotherapy in breast cancer cell lines and if a combination of imatinib with standard chemotherapy could lead to increased cytoreduction.
\end{abstract}

Methods: Colony-forming tests of MCF 7 and MDA MB 231 were used to study differences in cell proliferation under incubation with imatinib and radiation. Changes in expression and phosphorylation of target receptors were detected using western blot. Cell proliferation, migration and apoptosis assays were performed combining imatinib with doxorubicin.

Results: The combination of imatinib and radiotherapy showed a significantly stronger inhibition of cell proliferation compared to single radiotherapy. Differences in PDGFR expression could not be detected, but receptor phosphorylation was significantly inhibited when treated with imatinib. Combination of imatinib with standard chemotherapy lead to an additive effect on cell growth inhibition compared to single treatment.

Conclusions: Imatinib treatment combined with radiotherapy leads in breast cancer cell lines to a significant benefit which might be influenced through inhibition of PDGFR phosphorylation. Combining imatinib with chemotherapy enhances cytoreductive effects. Further in vivo studies are needed to evaluate the benefit of Imatinib in combination with radiotherapy and chemotherapy on the treatment of breast cancer.

\section{Background}

Breast cancer is the most common malignant tumour in women. Albeit further increases in incidence, breast cancer related mortality has been reduced by screening and early detection programs, as well as optimized therapeutic options. Besides surgery, chemotherapy and radiotherapy, targeted therapies including endocrine, small molecule and antibody related therapies have been able to improve patient outcome [1-5].

In early and advanced breast cancer, radiotherapy is a common part of standard therapies. External beam

\footnotetext{
* Correspondence: cmundhenke@hotmail.com

'Department of Obstetrics and Gynecology, Breast Center, University of Kiel, Arnold-Heller Strasse 3, 24105 Kiel, Germany

Full list of author information is available at the end of the article
}

radiotherapy (50 Gy, fraction dose 1.8 - 2 Gy, delivered over 30 - 35 days) is used for chest wall and total breast irradiation $[6,7]$.

Radiotherapy targets intracellular DNA and causes strand breaks. The ability of tumour cells to repair radiotherapy modulated DNA breaks is limited. Unrepaired DNA breaks commonly lead to apoptosis, necrosis, cell cycle arrest or mitotic inactivity. Radio sensitivity depends on intrinsic factors, defined by genetic determination as well as on extrinsic factors like growth receptor signalling and their chemical or biological modulations [8].

Membrane tyrosine kinases play a key role in cell signalling. Aberrant expression or activation has an impact on breast cancer oncogenesis and progression. Tyrosine 
kinase inhibitors show activities against one or multiple targets and are able to inhibit tumour proliferation and in some cases angiogenesis at the same time [9].

Imatinib mesylate $\left(\right.$ Glivec $\left.^{\oplus}\right)$ was originally developed for tailored inhibition of the oncoprotein bcr-abl in chronic myeloid leukaemia (CML) and is today part of CML standard therapies. Besides abl and bcr-abl, imatinib also inhibits the activation of PDGFR $\alpha, \beta$ and c-kit and is currently used in research and treatment of solid tumours [10-13].

Cell lines from different solid tumours with c-kit and/ or PDGFR expression have been tested previously for their response to imatinib. Cell growth of c-kit expressing cell lines of colon and small cell lung cancer could be inhibited in vitro and in vivo [14]. PDGFR activation occurs via an autocrine pathway or by ligands. Activation of PDGFR $ß$ enhances chemotaxis, while cell motility is decreased after PDGFR $\alpha$ activation. Inhibition of both subtypes leads to apoptosis. Co-expression of PDGFR $\beta$ and stimulating ligands can be seen in many malignant lesions [15-19]. Immunohistochemistry revealed a broad PDGFR expression in breast cancer $[20,21]$. Increased expression of PDGF receptors correlates with an increased risk of distant metastasis, decreased response to chemotherapy and reduced overall survival $[22,23]$. In murine breast tumours inhibition of activated PDGFR $\beta$ by imatinib leads to reduction in tumour cell growth [20].

Imatinib has also an antiangiogenic effect and leads to apoptosis in tumour and endothelial cells by blocking PDGF-B signalling pathways [24-28]. In highly angiogenic glioblastomas imatinib showed radiosensitizing activity. Additionally an imatinib related inhibition of PDGFR $\beta$ activation leads to a decrease in the interstitial pressure of solid tumours. This effect promotes an intracellular up-take of substances like cytotoxic agents $[29,30]$. Therefore it was suggested to introduce imatinib into clinical research and therapies of solid tumours like breast cancer expressing the specific cellular targets. Expression patterns of tyrosine kinases, relevant for imatinib action, have been described in human breast cancer cell lines previously. It is likely, that imatinib action in solid tumours is related to PDGFR $\beta$ inhibition [31]. Our hypothesis was that imatinib could contribute to breast cancer therapy by serving as a potential chemoand radiosensitizer.

\section{Methods}

\section{Cell Culture}

Human breast cancer cell lines (MCF 7 and MDA MB 231) were obtained from American Type Culture Collection, Rockville, USA. Cells were grown in RPMI 1640 medium containing $10 \% \mathrm{FBS}$ and $1 \%$ penicillin/streptomycin at $37^{\circ} \mathrm{C}$ and $5 \% \mathrm{CO}_{2}$. Their tyrosine kinase receptor and corresponding ligand expression patterns have been described previously [31].

\section{Ligand dependent proliferation and migration}

Cells for proliferation assays were seeded at a density of 10,000 cells $/ \mathrm{ml}$ on a 96 -well plate. After an attaching period of 24 hours, medium was exchanged for medium containing only $1 \%$ FCS to reduce effects of included growth factors. Cell lines were incubated either with PDGF BB (R\&D Systems, Minneapolis, MN, USA) (10, $25,50,75$ or $100 \mathrm{ng} / \mathrm{ml}$ ) alone or in combination with imatinib mesylate (IC50 $6 \mu \mathrm{M}$, defined previously $[31,32]$ ) (generously provided by Novartis, Basel, Switzerland) which was added before application of PDGF BB. Medium was replaced every 48 hours. After six days of incubation, experiments were terminated using Cell Titer Aqueous One Solution Reagent (Promega) and cell proliferation was measured. For migration assays silicon spacers were inserted into 12 -well plates before cells were seeded. At the point of cell confluency, spacers were removed and distances between migration fronts were measured. Cells were incubated with imatinib, PDGF BB ( $25 \mathrm{ng} / \mathrm{ml})$ or their combination for 72 hours and cell migration was measured every 24 hours using Axio vision software (Zeiss, Germany). Experiments were set up in triplicates and performed three times to confirm results. For statistical analysis student's t-test was carried out and p-values $<0.05$ were declared significant.

\section{Cell proliferation combining imatinib mesylate and doxorubicin}

Cells were plated on 12-well plates and were allowed to attach for 24 hours. Then, cells were incubated with doxorubicin (Sigma-Aldrich, St Louis, MO, USA) in concentrations of $0.25 \mathrm{nM}-12.5 \mathrm{nM}$ and imatinib $(1.5-12 \mu \mathrm{M})$ alone and in combinations. Replacement of medium was carried out every 48 hours and cell proliferation was determined by trypsinization, trypan blue staining and cell counting after six days. Experiments were set in triplicates and repeated to confirm results. Drug interaction was assessed using the combinatory index, where $\mathrm{CI}<1, \mathrm{CI}=1$ and $\mathrm{CI}>1$ indicate synergistic, additive and antagonistic effects. Data analysis was carried out using the Calcusyn Software (Biosoft, Oxford, UK)[32,33].

\section{Apoptosis analysis}

Breast cancer cell lines were seeded on chamber slides (MDA MB 231 20,000 cells/ml, MCF 7 40,000 cells/ml) and after attachment over night, cells were incubated with imatinib (IC50 $6 \mu \mathrm{M}$ ), doxorubicin (1 nM, 2,5 nM and $5 \mathrm{nM}$ ) or the combination of both drugs for 24 and 48 hours. Slides were washed with PBS, cells were fixed 
with 4\% paraformaldehyde and TUNEL assay was carried out according to manufacturer's protocol. Apoptotic cells were counted in five random fields using fluorescence microscopy and expressed as percentage of total cell number. Student's t-test was used for statistical analyses and p-values $<0.05$ were declared significant.

\section{Radiation in vitro}

Cells were cultured in $\mathrm{T} 75$ cell culture flasks and seeded at a density of 4,000 (MDA MB 231) and 10,000 (MCF 7) cells/ml. After 24 hours of attaching, cells were incubated with or without imatinib in concentrations of 4 or $6 \mu \mathrm{M}$. Radiation was performed after another 24 hours using a telecobalt source (Theatron 780C, Phillips) emitting gamma radiation produced by cobalt 60 with energy of $1.33 \mathrm{MeV}$. In previous experiments a difference between radiation using cobalt 60 or iridium 192 could not be detected (data not shown). During radiation and transport, cells were stored in a specially designed isolated box guaranteeing a constant temperature of $37^{\circ} \mathrm{C}$. A total dose of $10 \mathrm{~Gy}$ was applied fractionated in doses of 2 Gy per day on 5 consecutive days. Cells were counted using the trypan blue method 24 hours after each fraction. All experimental points were set-up in triplicates and repeated at least twice to confirm results.

\section{Colony forming test}

Colony forming tests were carried out to detect the effect of radiation on cell vitality. $1 \mathrm{~g}$ of bactoagar (Becton, Dickinson \& Co., Sparks, MD, USA) was boiled in $20 \mathrm{ml}$ pure water and suspended with $20 \mathrm{ml}$ culture medium. Separately 1,000 MDA MB $231 \mathrm{cells} / \mathrm{ml}$ and $3,000 \mathrm{MCF} 7$ cells $/ \mathrm{ml}$ were added at $37.5^{\circ} \mathrm{C}$. Different set-ups were used for each dose level. After polymerization the agar was covered with $2 \mathrm{ml}$ of cell culture medium. Medium changes took place every seven days and after 10 (MDA MB 231) and 21 (MCF 7) days of incubation. Colonies consisting of more than 30 cells were counted. Plating efficiency was calculated by multiplying the number of colonies by 100 and dividing it by the number of cells plated. To determine the surviving fraction the number of colonies of treated cells was divided by the number of colonies of non radiated control cells. Statistical analysis was performed using the student's ttest and p-values $<0.05$ were declared significant.

\section{Immunoblotting}

To detect the influence of radiation and imatinib cotreatment on receptor activation, cells were lysed in lysis buffer (62.5 mM Tris-HCL (pH 6.8), 2\% SDS, $50 \mathrm{mM}$ DTT and $10 \%$ glycerol) and proteinase inhibitor was added. Protein determination was carried out using the Bradford method (Bio-Rad, Hercules, CA, USA). $30 \mu \mathrm{g}$ of total protein were separated depending on molecular weight in SDS-PAGE. After transfer onto PVDF-membranes, membranes were blocked and incubated with primary antibody. Primary antibodies used were rabbit polyclonal anti-PDGFR $\beta$ (Santa Cruz Biotechnology, Santa Cruz, CA), rabbit polyclonal anti-phospho-PDGFR $\beta$ (Cell Signalling Technology, Danvers, MO, USA) and anti- $\beta$-actin (Sigma-Aldrich). After incubation with corresponding secondary horseradish peroxidase-conjugated antibodies, blots were developed using the ECL-system (Amersham Biosiences, Piscataway, NJ, USA).

Research reported has been carried out with the agreement of the ethics committee of the University of Kiel, Germany (AZ D 426/10).

\section{Results}

In previous experiments we could determine that the cell lines used express receptors which are known imatinib targets. All cell lines express PDGFR $\beta$ and abl. MCF 7 cells are positive for c-kit and PDGFR $\alpha$ is expressed by MDA MB 231. Despite their different expression patterns, imatinib has an anti-proliferative effect on both breast cancer cell lines with an IC 50 concentration of $6 \mu \mathrm{M}[31,34]$.

\section{Imatinib inhibits PDGF BB dependent cell proliferation and migration}

In MDA MB 231 cells stimulation with PDGFR $\beta$ specific ligand PDGF $\mathrm{BB}$ in concentrations of $10 \mathrm{ng} / \mathrm{ml}$ leads to an increased cell growth of 186 percent. Higher ligand concentrations are not able to induce incremental cell proliferation (Figure 1). On the other hand imatinib is able to reduce the proliferative effect of PDGF BB. MCF 7 cells react differently on growth factor application. PDGF BB induces a cell growth increase of about $20 \%$ among all concentrations used and imatinib is able to reduce cell proliferation by $50 \%$. The cell growth factor PDGF BB increases cell growth in breast cancer cell lines. Response rates to ligand specific signal-transduction vary, but imatinib is able to exert its anti-proliferative effect on all breast cancer cells in spite of PDGF BB stimulation.

MDA MB 231 cells show an increase in cell migration compared to the control upon stimulation with PDGF $\mathrm{BB}$ (Figure 2). Imatinib has the ability to inhibit cell migration in the absence of PDGF BB and this effect is also apparent in the presence of growth factor stimulation. In contrast, PDGF BB does not significantly alter cell migration of MCF 7 breast cancer cells, but imatinib reduces their migration significantly at 48 hours and as well at 72 hours of incubation. The tyrosine kinase inhibitor imatinib reduces cell migration of the studied breast cancer cell lines significantly and this anti-migratory effect persists in the presence of PDGF BB stimulation. 


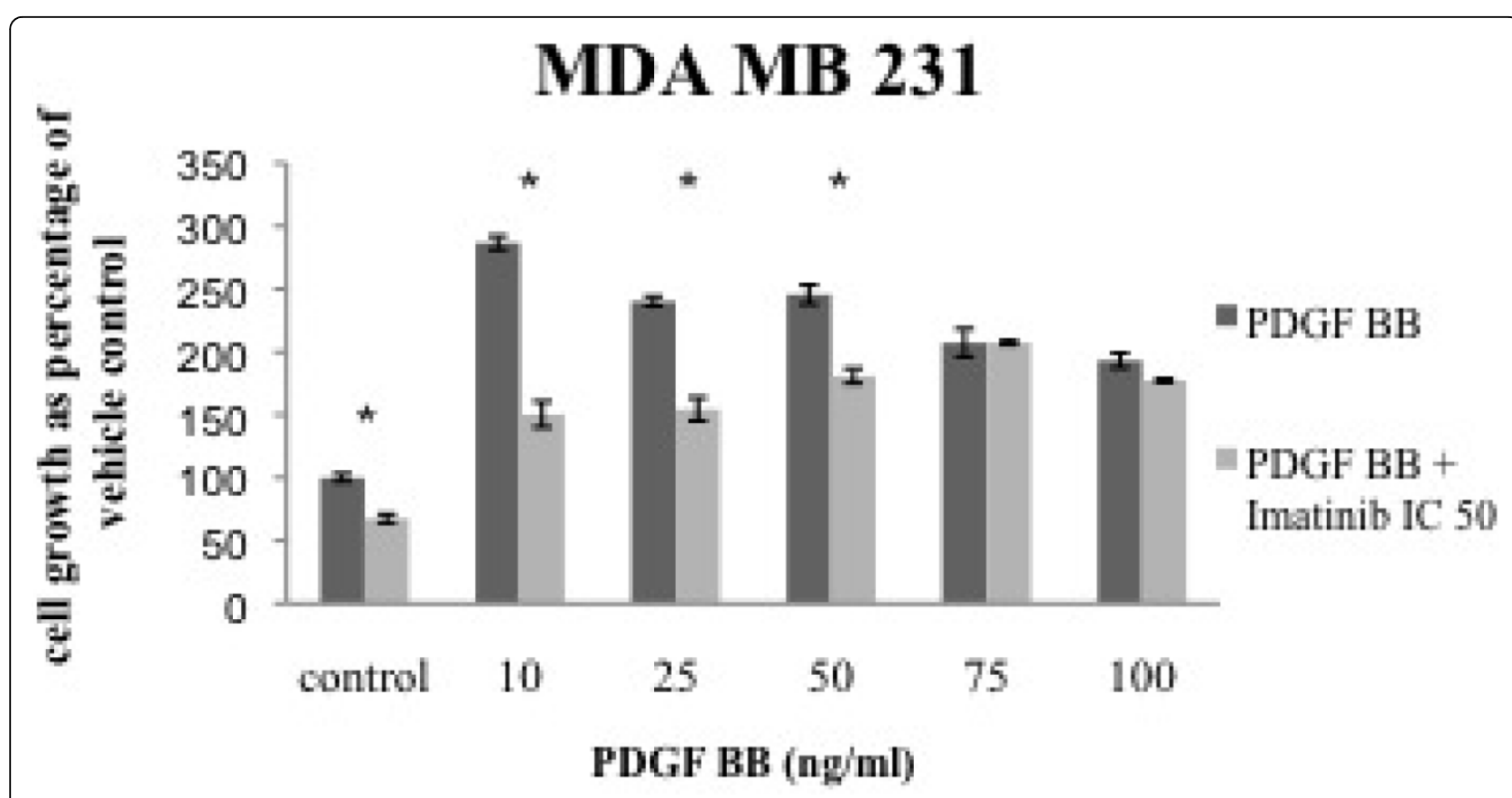

\section{MCF 7}

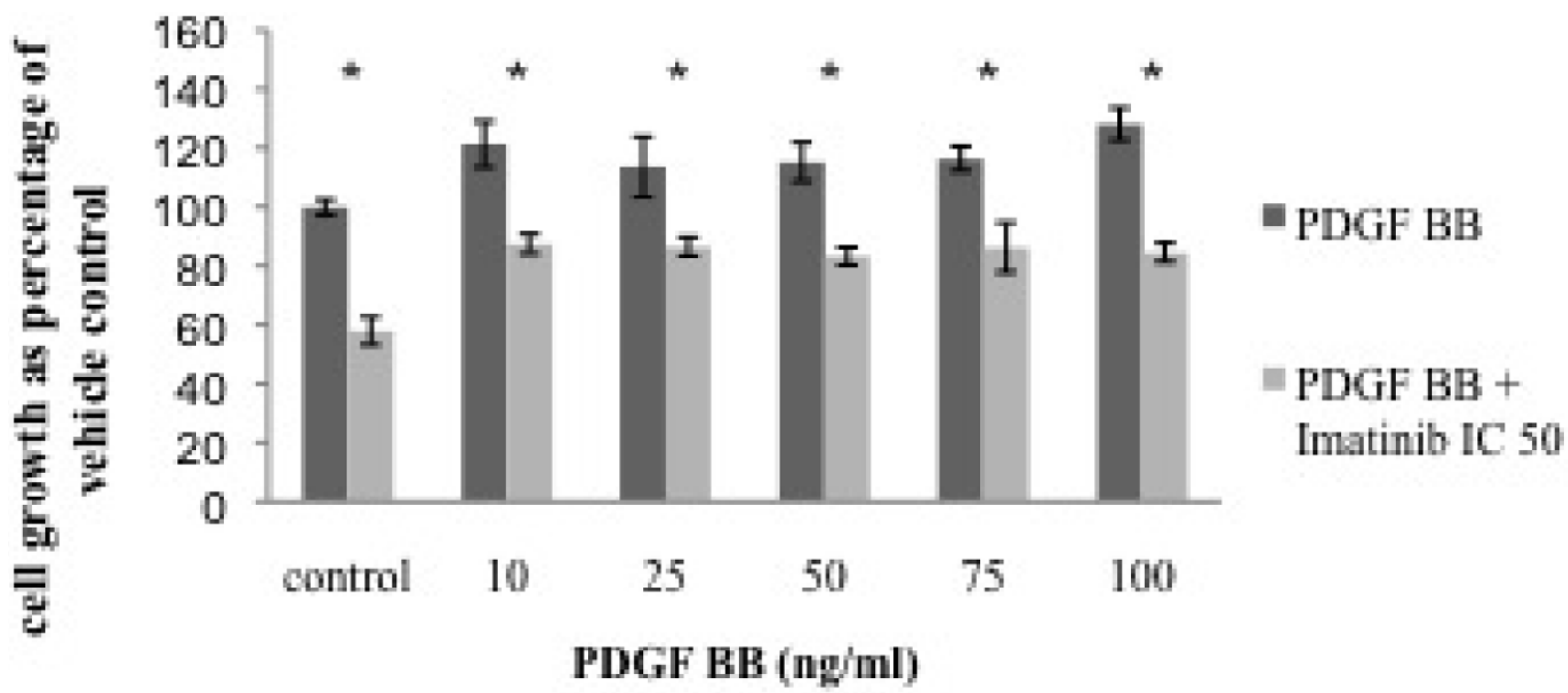

Figure 1 Imatinib inhibits PDGF BB dependent cell proliferation in breast cancer cell lines. Cells were incubated with increasing concentrations of PDGF BB and imatinib (IC 50). Cell growth was measured by MTT-assay.

Combination of imatinib and doxorubicin leads to enhanced cell growth inhibition

This experiment was set-up to detect if imatinib might be a useful add-on to the cytotoxic drug doxorubicin which is used in different therapeutic settings in breast cancer treatment. Therefore cells were incubated with increasing concentrations of doxorubicin and imatinib alone or in combination (Figure 3). Dose ratios were applied and combination indices were calculated (Table 1 ). An additive effect on cell proliferation can be detected in MDA MB 231 cells using a dose ratio of 1:6,000 (doxorubicin:imatinib), which contains the IC50 


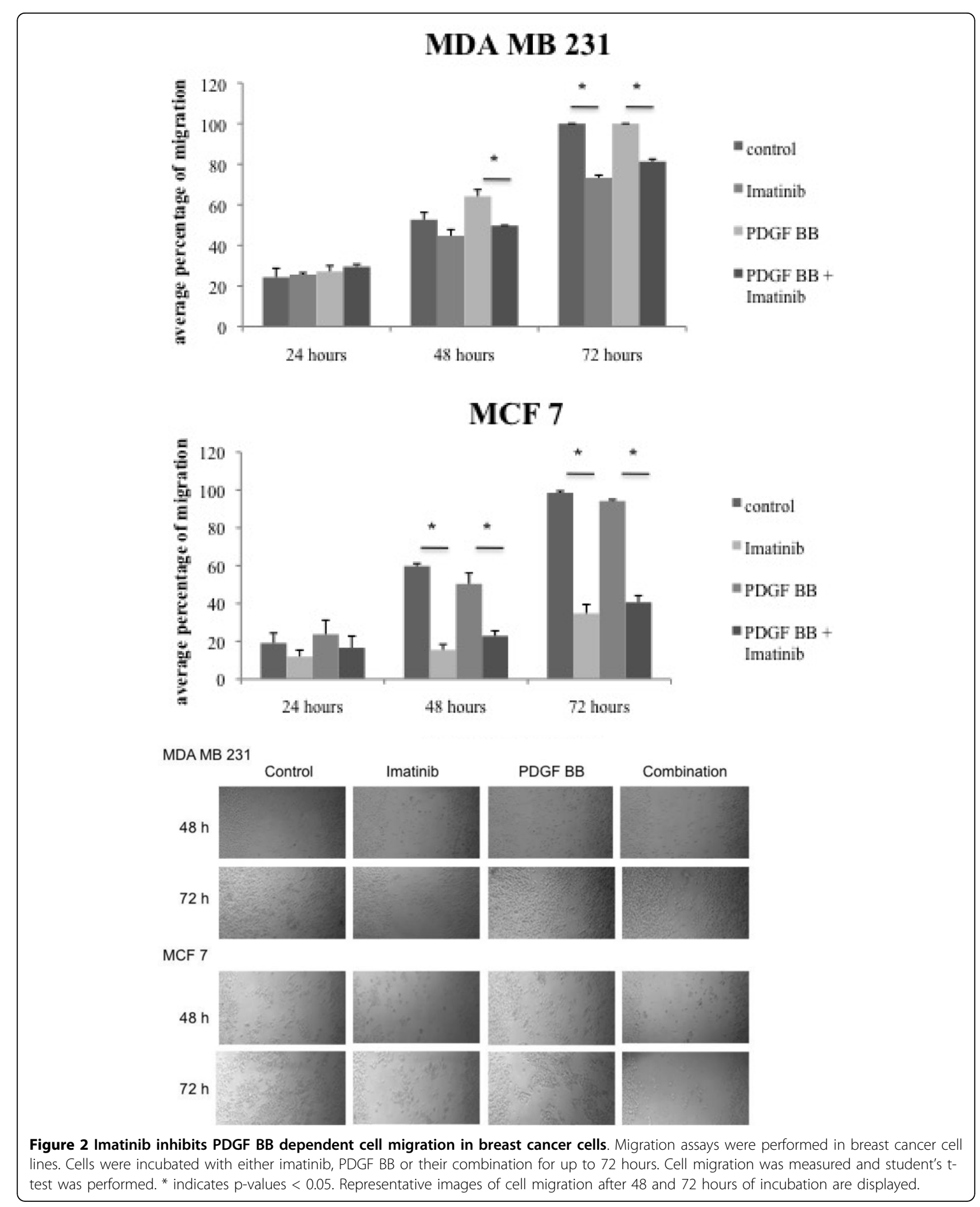




\section{MDA MB 231}

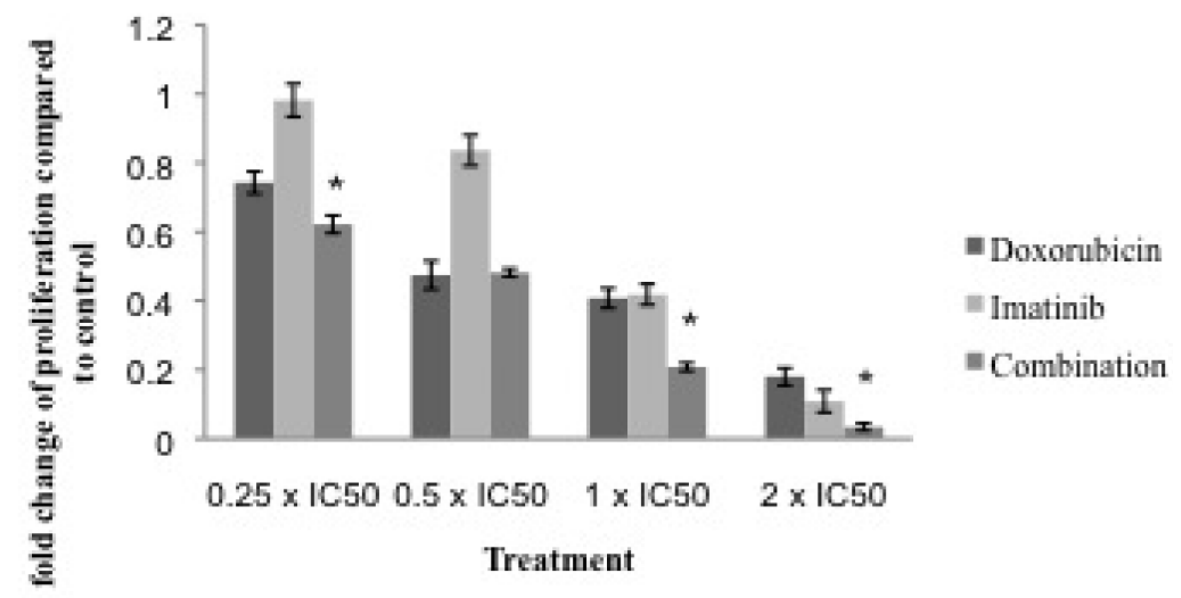

MCF 7

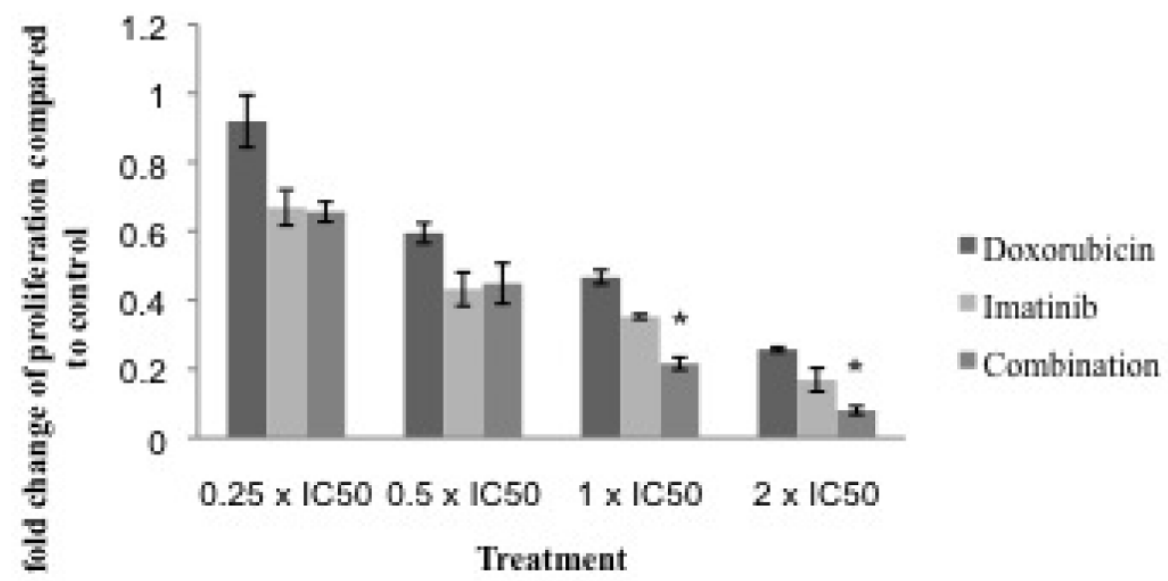

Figure 3 Combination of imatinib with doxorubicin leads to enhanced cell growth inhibition. Cells were incubated with doxorubicin or imatinib alone or in combination. Cell proliferation was assessed after six days of incubation. Combination indices were calculated using Calcusyn software. ${ }^{*}=$ p-value 0.05 determined by student's t-test.

of both drugs. Among MCF 7 cells the combination reaches an additive effect in higher dose ranges, whereas the combination of doses lower than the IC50 shows an antagonistic effect. Both therapeutic drugs show an additive effect on cell growth inhibition when combined, which is pronounced in the triple negative MDA MB 231 cell line.

\section{Imatinib's effect on cell apoptosis}

To determine whether the combination of imatinib with doxorubicin leads to increased levels of cells undergoing apoptosis, TUNEL assays were carried out. Incubation of MDA MB 231 cells with imatinib induces apoptosis in 12 and $10 \%$ of cells after 24 and 48 hours. Cells incubated with doxorubicin over the same time show an apoptotic rate of $5 \%$ and $14 \%$. The combination of both drugs does not increase the level of cells undergoing apoptosis at these specific time points (Figure 4). In contrast, apoptotic rates in the hormone receptor positive MCF 7 cells rise to comparable levels after 24 hours of incubation with either drug alone or their combination. Moreover, after 48 hours the amount of apoptotic cells decreases in imatinib and doxorubicin treated cells (11\% and $15 \%)$, whereas the combination shows an increase in apoptotic cells to $34 \%$. Imatinib and doxorubicin lead to apoptosis induction in both cell lines, but 
Table 1 Combination indices calculated for imatinib and doxorubicin co-incubations in breast cancer cell lines

\begin{tabular}{lllllll}
\hline MDA MB 231 & \multicolumn{1}{l}{} & & \\
\hline Drug & \multicolumn{2}{l}{ Combination Index Values at } & & Dm (nM) & m & \\
& ED 50 & ED 75 & ED 90 & & & \\
\hline Combination (1:6000) & 1.11214 & 1.01224 & 0.99765 & 0.39732 & 1.84658 & 0.96979 \\
Doxorubicin & N/A & N/A & N/A & 0.57999 & 1.15437 & 0.97662 \\
Imatinib & N/A & N/A & N/A & 5581.5821 & 2.92342 & 0.99784 \\
\hline
\end{tabular}

MCF 7

\begin{tabular}{lllllll}
\hline Drug & \multicolumn{2}{l}{ Combination Index Values at } & & Dm (nM) & m & r \\
& ED 50 & ED 75 & ED 90 & & & \\
\hline Combination (1:1200) & 1.32605 & 1.10981 & 0.95853 & 2.03607 & 1.48647 & 0.99769 \\
Doxorubicin & $\mathrm{N} / \mathrm{A}$ & $\mathrm{N} / \mathrm{A}$ & $\mathrm{N} / \mathrm{A}$ & 4.56443 & 1.58527 & 0.96108 \\
Imatinib & $\mathrm{N} / \mathrm{A}$ & $\mathrm{N} / \mathrm{A}$ & $\mathrm{N} / \mathrm{A}$ & 7487.20892 & 1.04304 & 0.98481 \\
\hline
\end{tabular}

ED 50 (effect dosis 50\%), Dm (IC50) calculated, m (measures of sigmoidicity), $r$ (correlation coefficient)

only in MCF 7 cells a further increase in apoptosis can be detected when drugs are combined.

\section{Effects of radiation on breast cancer cells}

To detect the effect of irradiation on breast cancer cell lines, the estrogen receptor (ER) positive cell line MCF 7 and the ER negative cell line MDA MB 231 were selected. Fractionated radiation with 2 Gy per day on 5 following days to reach a total dose of 10 Gy was performed. The surviving fraction of each dose level was determined. Both cell lines show a decrease in the surviving fraction which correlates with the increasing dose levels (Figure 5). The decrease is stronger in the highly proliferative MDA MB 231 cell line.

\section{Combination of imatinib with irradiation reduces breast cancer cell growth}

To evaluate if imatinib could enhance the effect of radiation on breast cancer cells, cells received either single radiation, imatinib incubation (IC50) or the combination of both. The surviving fraction was measured after each dose level (Figure 5). Regarding the surviving fractions of MDA MB 231 cells, imatinib is able to reduce the surviving fraction further when combined with irradiation. These effects can also be seen in the lower proliferating cell line MCF 7. Here the combined treatment leads to a decrease of the surviving fraction which is explicitly detectable after application of higher Gy levels. Compared to each single treatment, the combined application of irradiation and imatinib further reduces the number of surviving and colony forming cells.

\section{PDGFR $\beta$ expression is not effected by irradiation and imatinib}

As the PDGF receptor $\beta$ is expressed by all cell lines we decided to further investigate the modulation of this receptor by imatinib. To detect if changes in PDGFR $\beta$ expression occur after imatinib treatment and/or fractionated irradiation, western blot analysis was performed following different treatment modalities. After each treatment option, protein lysates were extracted. As shown in figure 6, the expression of the tyrosine kinase receptor PDGFR $\beta$ is not modified by the different treatment options in MCF 7 and MDA MB231 breast cancer cell lines.

Imatinib causes PDGFR $\boldsymbol{\beta}$ inactivation in combination with irradiation

Modulation and inhibition of the PDGFR $\beta$ signalling pathway by imatinib can be measured by the receptor phosphorylation status. Tests were carried out after single incubation with imatinib and in combination with irradiation. MCF 7 cells show an inhibition of receptor activation when imatinib in a concentration of $6 \mu \mathrm{M}$ is combined with irradiation (Figure 7). An effect of single imatinib incubation on receptor phosphorylation could not be detected in this experimental set-up. In contrast to these results imatinib is able to inhibit PDGFR $\beta$ phosphorylation in MDA MB 231 cells. After incubation with imatinib in concentrations of 4 and $6 \mu \mathrm{M}$ receptor activation is blocked. In irradiated breast cancer cells this effect on receptor inactivation is consistent.

\section{Discussion}

The aim of this study was to detect which effect the tyrosine kinase inhibitor imatinib mesylate has on breast cancer cell lines in vitro when combined with either chemotherapy or irradiation. Further it was examined how imatinib modulates the PDGFR $\beta$ signalling pathway. For this purpose, expression patterns of imatinib specific target receptors PDGFR $\alpha, \beta$, c-kit and their according ligands PDGF $\mathrm{A}, \mathrm{B}$ and $\mathrm{H}-\mathrm{SCF}-1$ were examined. While PDGFR $\beta$ was detectable among all cell lines, PDGFR $\alpha$ was not expressed by MCF 7 cells in 


\section{MDA MB 231}
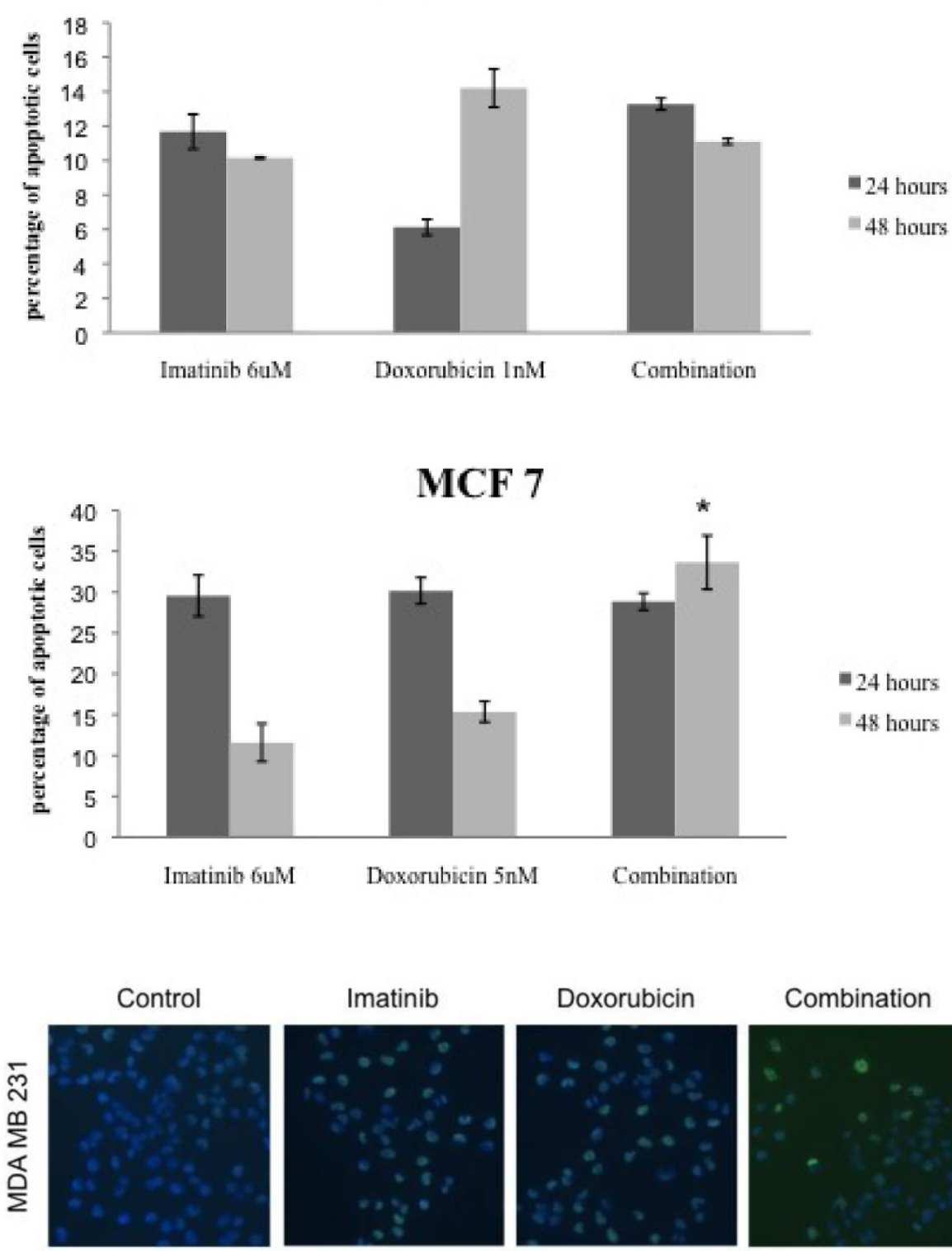

Combination
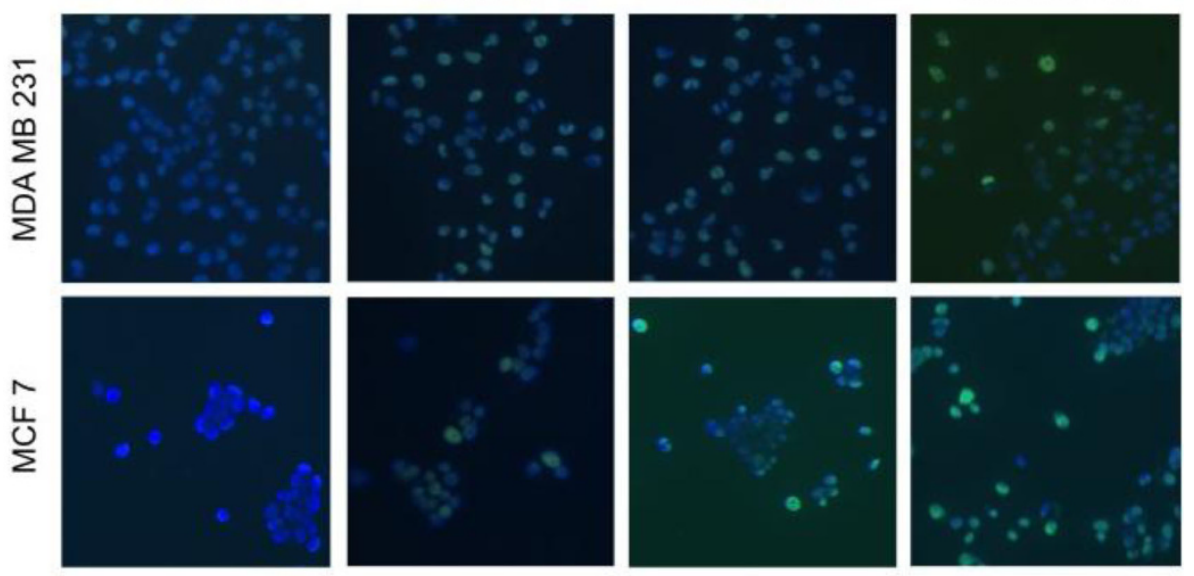

Figure 4 Effect of imatinib and doxorubicin on apoptosis of breast cancer cells. Cells were incubated with imatinib, doxorubicin alone or their combination for 24 and 48 hours. Apoptotic fraction was estimated by TUNEL assay and apoptotic cells were counted using fluorescence microscopy. For each sample, a total of five times 200-500 cells were scored and apoptotic fractions are expressed as percentage of total cells counted. Apoptotic cells show a green nuclear staining compared to vital cells. 


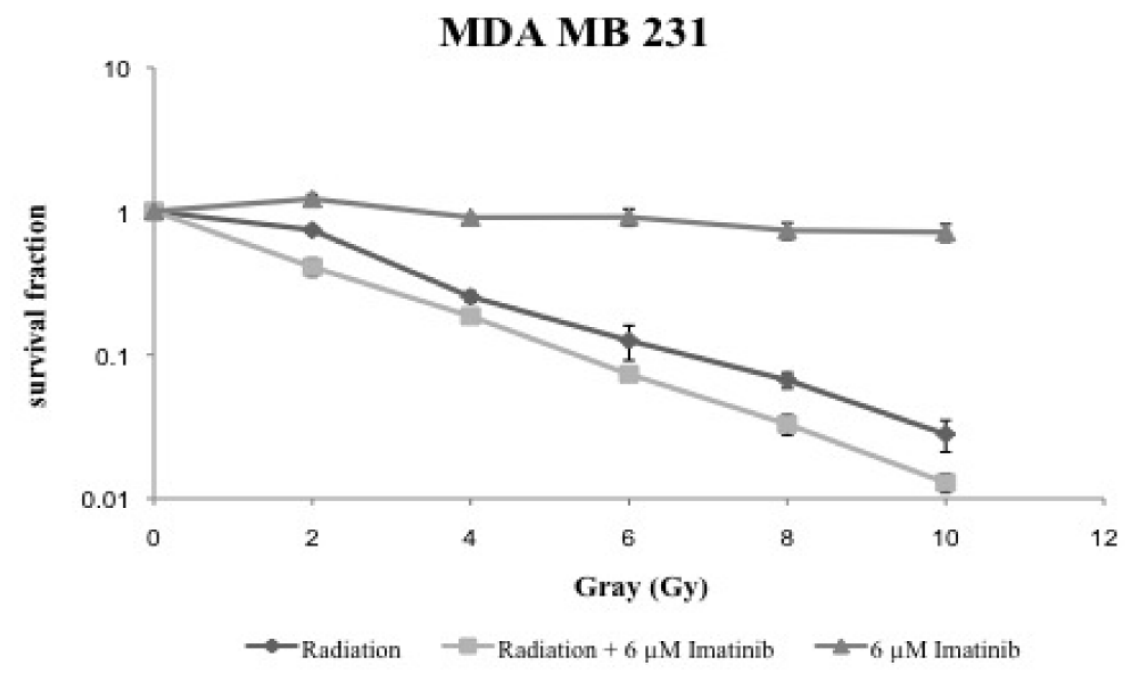

MCF 7
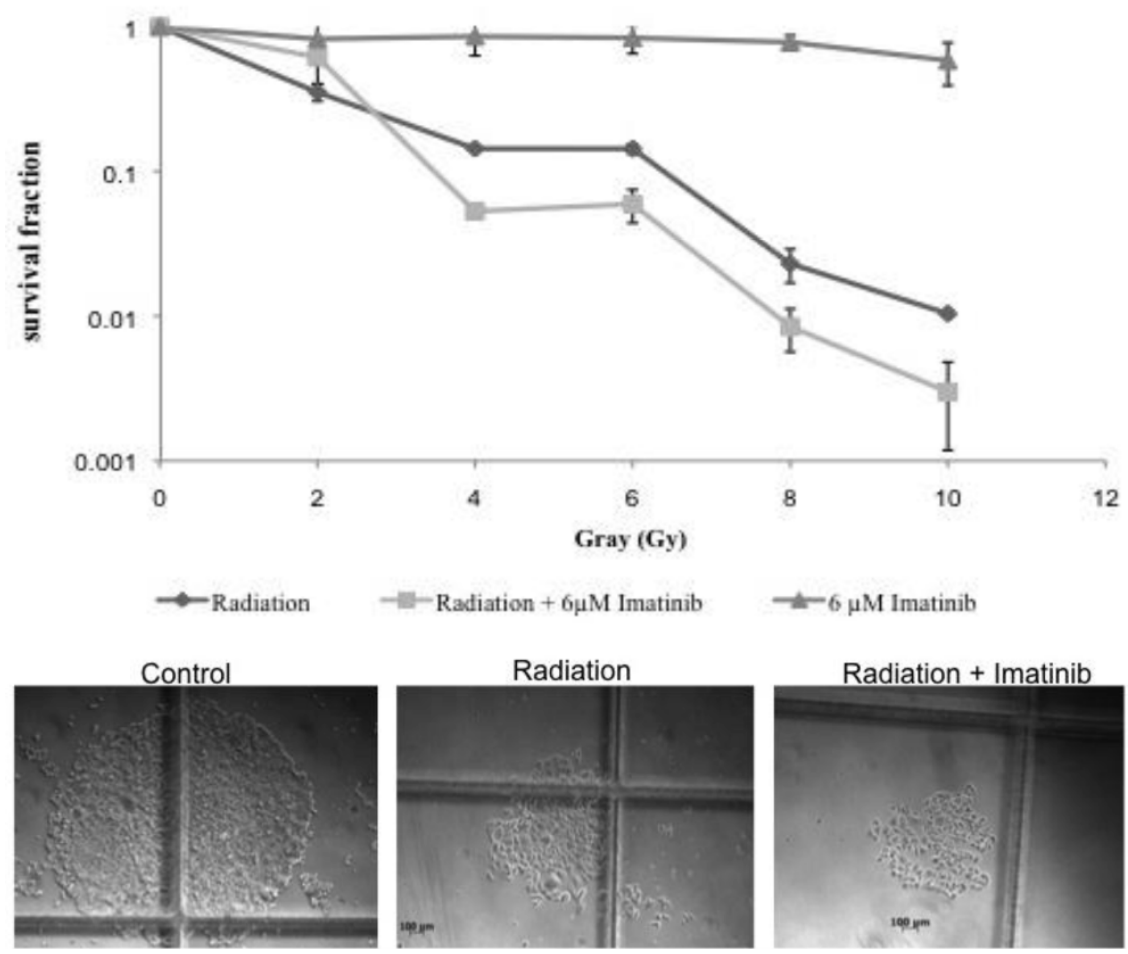

Figure 5 Combination of imatinib with irradiation reduces breast cancer cell growth in vitro. Cells were incubated with imatinib alone, received irradiation of 2 Gy per day for 5 days or the combination of both. Colony-forming tests were performed and the surviving fraction was calculated dividing the number of colonies of treated cells by the number of colonies of non radiated control cells. Representative colonies of MCF 7 cells are shown.

this setting, but they were positive for c-kit. The ligands PDGF A and B were transcribed by both cell lines and H-SCF-1 only by MCF 7. These expression patterns correspond with other studies which describe an expression of the ligand PDGF A but not the PDGFR $\alpha$ receptor by MCF 7 cells [35]. So far only few groups have performed immunohistochemical analysis in primary breast cancers on PDGFR expression which plays an important role in autocrine and paracrine stimulation of cancer and stromal cells as well as in angiogenesis [13]. An expression of PDGFR $\alpha$ could be detected in $40 \%$ of ductal invasive breast cancers and more than $80 \%$ of 
MCF 7
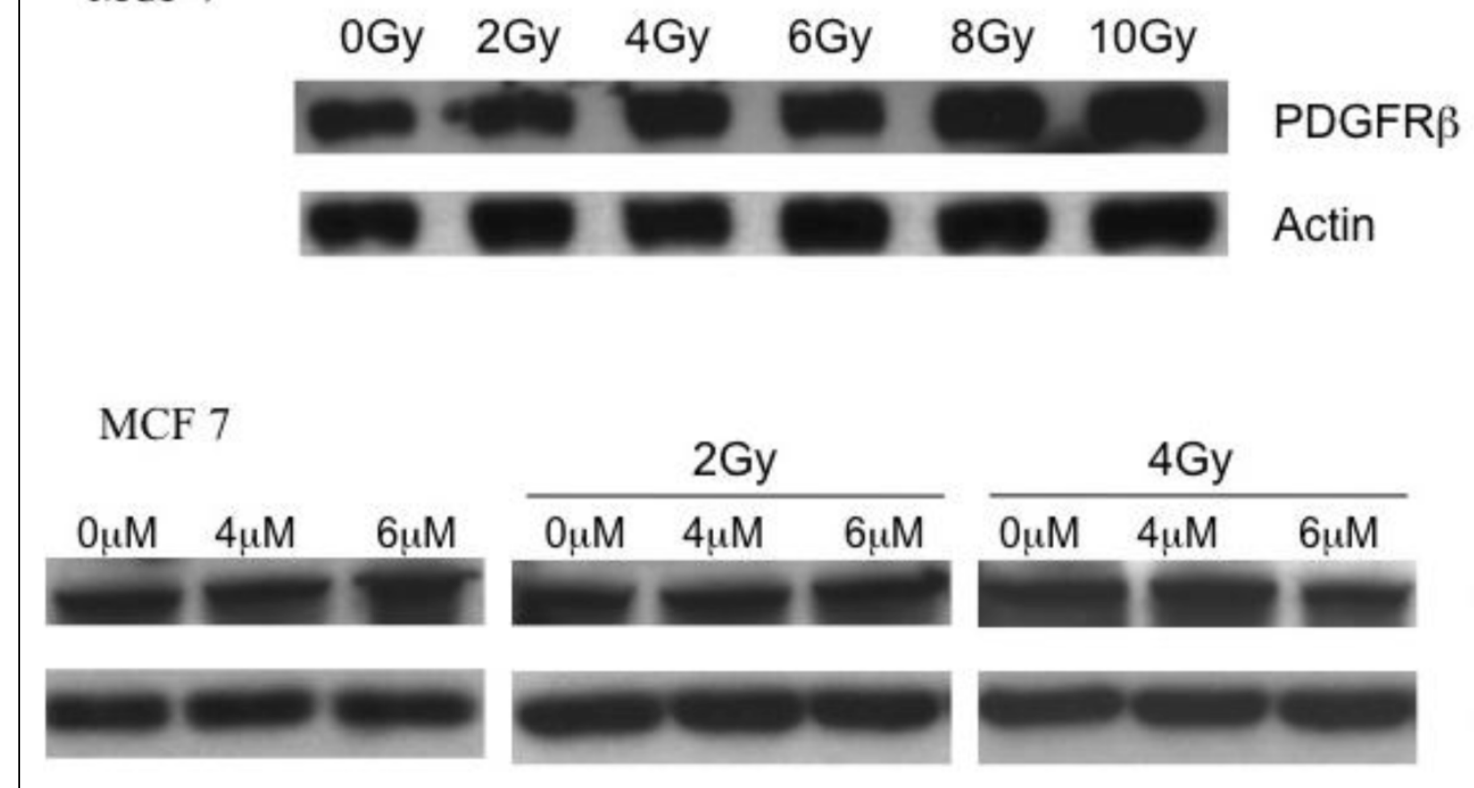

PDGFR $\beta$

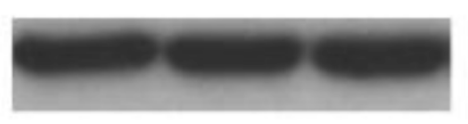

Actin
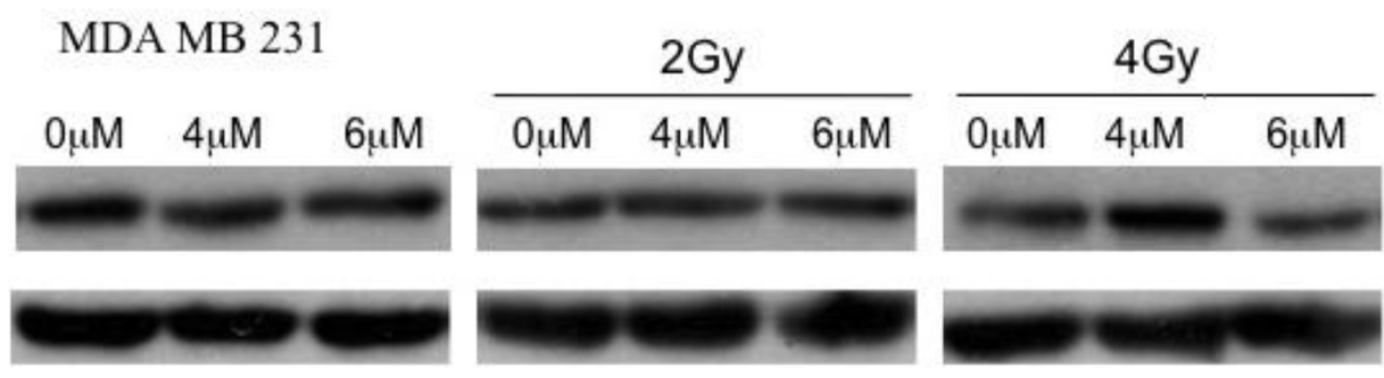

PDGFR $\beta$

Figure 6 PDGFR $\beta$ expression is not effected by irradiation and imatinib. Breast cancer cell lines underwent irradiation, incubation with imatinib or the combination of both. Total protein was extracted and western blot was carried out using antibodies against PDGFR $\beta$.

these showed also a PDGF A translation. A positive correlation between receptor expression and axillary lymph node metastasis has been suggested [35]. PDGFR $\beta$ is expressed in endothelial cells of ductal carcinoma in situ [36] and also of prognostic value in peritumoral stroma [37]. Positivity has been reported for over $50 \%$ of invasive carcinoma cells.

Furthermore, autocrine stimulation of PDGF receptors is reported as an important factor in tumor progression and metastasis [38,39]. Likewise poor overall survival rates and low response to chemotherapy are correlated with over-expression of PDGF receptors [23]. Therefore by targeting these receptors, imatinib might be able to inhibit local tumour growth and decrease metastatic potential.

In previous studies we were able to determine a cell growth inhibition of imatinib on breast cancer cell lines in clinically relevant concentrations of 4 to $6 \mu \mathrm{M}$ which could be confirmed by other groups [31,34]. In other cancer entities such as pancreatic cancer or medullary cancer of the thyroid gland higher concentrations were needed to cause cell growth inhibition in vitro which might be due to different receptor expression patterns $[40,41]$. Oral application of 25-600 mg imatinib can lead to plasma levels of about $0.17-5.68 \mu \mathrm{M}$ in vivo [42]. Therefore in vivo effects of imatinib in breast cancer patients appear to be reasonable in a tolerable dose.

To further investigate the interaction of imatinib with growth signalling pathways, we have chosen the PDGFR $\beta$ axis because this receptor is expressed among both cell lines examined. Moreover it is not sure if c-kit activation mediates cell proliferation in breast cancer $[14,43]$. At least we were not able to detect an increased cell growth through SCF (c-kit ligand) application in previous experiments, whereas incubation with PDGF $\mathrm{BB}$ leads to augmented cell growth in all breast cancer cell lines and has the ability to stimulate cell migration. Similar results could be detected by other research groups who could show that PDGF BB application leads to increased cell growth whereas PDGF AA had no 


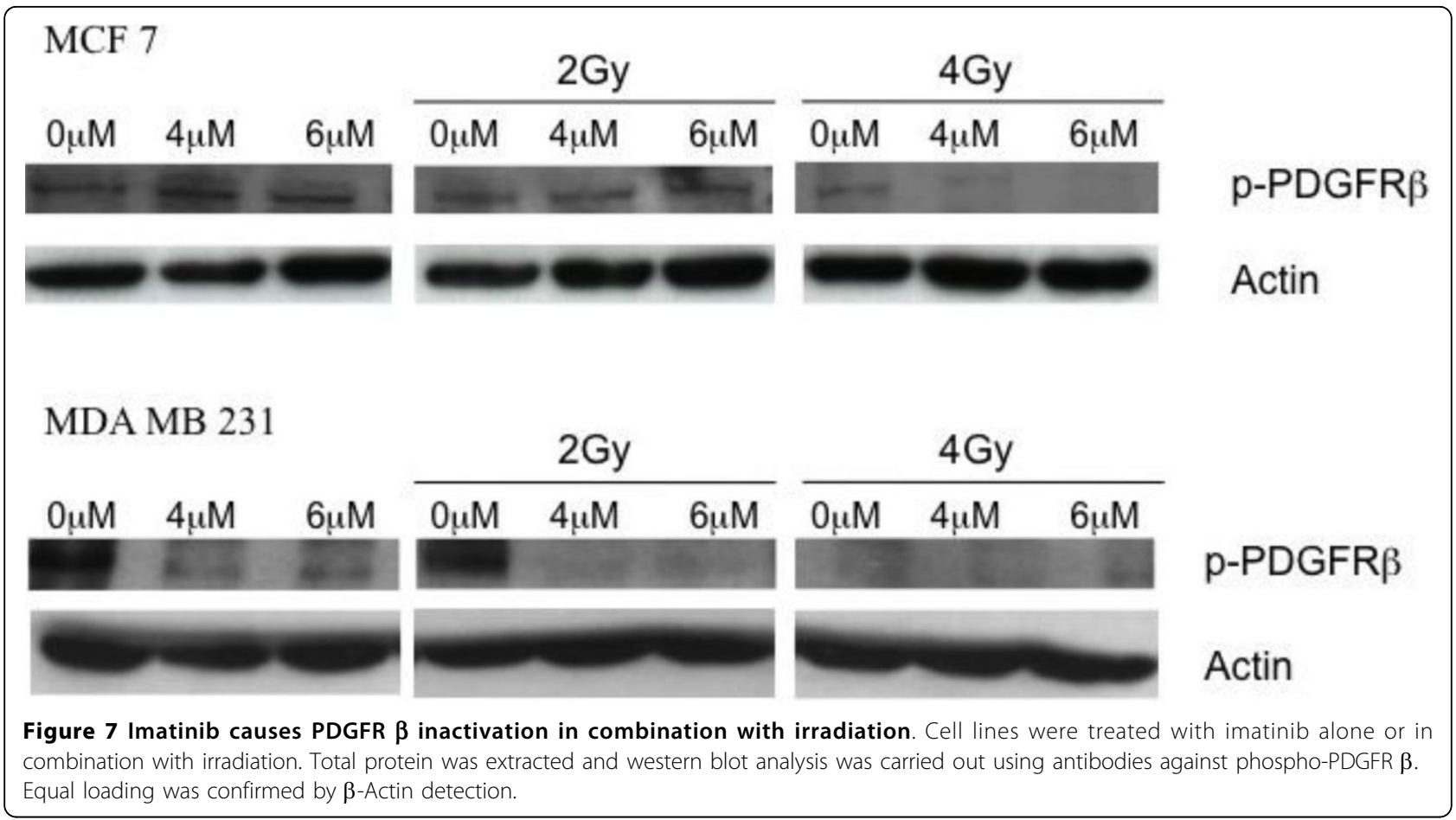

effect on cell proliferation [44]. Moreover, in ovarian and breast cancer cell lines an inhibition of PDGF BB generated PDGFR $\beta$ phosphorylation could be detected after imatinib incubation $[19,27,31]$.

PDGFR $\beta$ activation is known to cause a protective effect against the antiproliferative potential of chemotherapeutic drugs as paclitaxel and doxorubicin in various cancer entities $[28,45]$. For this reason, the effect of a combination of imatinib, as a PDGFR $\beta$ inhibitor, with chemotherapeutic drugs in breast cancer cells appeared to be promising. In previous experiments we could determine a significant cell growth inhibition when imatinib was combined with vinorelbine compared to a single vinorelbine treatment [31]. Moreover a combination of imatinib with cisplatin has an additive effect on cell growth inhibition [46]. In this experimental setting we studied the effect of imatinib in combination with doxorubicin, which is frequently used in the adjuvant and palliative therapy of breast cancer.

In combination with doxorubicin an increase in chemosensitivity due to the potential of imatinib to inhibit PDGFR $\beta$ could be demonstrated among feline vaccineassociated sarcomas [47]. In this experimental setting we were able to prove that imatinib, despite its potential of decreasing the interstitial pressure in tumours and enhancing anti-angiogenic effects in vivo, is able to alter the chemosensitivity of breast cancer cell lines in vitro. This is of major interest because clinical trials investigating the effect of imatinib either as a monotherapy or combined with docetaxel in metastasized breast cancer do not show significant results even if patients were selected according to PDGF receptor expression of tumour cells [48-50]. For this reason, it is important to perform further trials combining imatinib with chemotherapeutic drugs. A selection of patients expressing targets for imatinib treatment is of great relevance.

Irradiation is an important component of standard therapy in the adjuvant as well as in the metastasized setting of breast cancer. For this reason, we investigated the effect of irradiation and the combination with imatinib on breast cancer cell lines in vitro. Comparing the two breast cancer cell lines MCF 7 and MDA MB 231, there is some inhomogenity in the anti-proliferative effect caused by ionizing radiation. MDA MB 231 has a higher mitotic potential and therefore a higher plating efficiency compared to MCF 7. Moreover, the surviving fraction of MDA MB 231 compared to MCF 7 cells according to the radiation doses is diminished in the cell colony forming test. The demonstrated differences in radiosensitivity of both breast cancer cell lines correlate with formerly published results for unfractionated irradiation [51,52]. To investigate the effect of imatinib on radiosensitivity of breast cancer cell lines, cells were incubated with imatinib and a fractionated radiation was applied. Comparing the surviving fractions of cells undergoing radiation only or imatinib incubation only with the combination of both demonstrates that the combination treatment leads to a further decrease in 
cell survival in the two cell lines. The decrease is detectable among all dose levels of radiation. These results are similar to other investigations on radiosensitivity modulation through imatinib in different cancer cell lines in vitro [20,53-55]. The effect of a combination of imatinib and radiation was studied in particular in glioblastomas. Incubation with imatinib increases the radiosensitivity in glioblastoma cell lines whereas there is no detectable alteration among fibroblasts [56-58]. The effectivity of this combinatory treatment can not yet fully be explained. A possible explication might be an inhibition of the PDGF receptor pathway by imatinib, which interacts with the alterations of cell signalling, caused by radiation. By inhibiting the PDGF receptor signalling, there might occur a blockade of cell repair mechanisms which are important in repairing radiation induced damages like double-strand breaks on the DNA level. In PDGFR expressing glioblastoma cells the addition of imatinib to irradiation induced a significant increase of cells undergoing apoptosis. The effect of radiation could be improved through imatinib enhanced apoptosis rates [53].

As well as for chemotherapy, a high interstitial fluid pressure (IFP) is also a prognostic marker for poor response on irradiation [59]. For this reason a diminished IFP due to imatinib mediated PDGFR inhibition could be another mechanism to alter the effects of irradiation. We could show that there is no change in PDGFR $\beta$ expression when cells were incubated with single imatinib or in combination with radiation. Single irradiation has no effect on receptor activation whereas combination with imatinib leads to an inhibition of receptor phosphorylation in both cell lines. This effect was formerly described in other cancer entities like glioblastomas, ovarian cancer and small cell lung cancer $[10,19,60]$. According to our results, single radiation does not cause any changes in PDGFR $\beta$ activity in glioblastoma cells, whereas a direct correlation between imatinib induced inhibition of PDGFR $\beta$ phosphorylation and increased radiosensitivity was detected [57]. Imatinib is able to modify several different cell signalling pathways and has therefore diverse possibilities in modulating the effects of irradiation. It is certain that inhibition of the PDGFR $\beta$ pathway plays a decisive role in the enhancement of radiosensitivity in breast cancer cell lines.

\section{Conclusions}

Imatinib as a tyrosine kinase inhibitor has the ability to modulate receptor pathways. In our study we could demonstrate that imatinib is able to inhibit the autocrine and paracrine mediated activation of the PDGFR $\beta$ pathway and therefore to inhibit the PDGF BB induced proliferation as well as migration of breast cancer cell lines in vitro. In combination with the chemotherapeutic drug doxorubicin, an additive effect on the inhibition of cell proliferation could be detected. If combined with fractionated radiotherapy a decrease in the surviving fraction of breast cancer cells compared to single treatment is caused by imatinib. A possible explanation for this enhanced radio- and chemosensitivity seams to be the imatinib mediated inhibition of the PDGFR $\beta$ pathway.

Further clinical trials have to be performed to approve these effects on breast cancer in vivo. A strong selection of patients expressing targets for imatinib is required to survey the influence of imatinb in combination with radiation or chemotherapy in breast cancer patients. Overall the results of this study suggest imatinib to be a candidate as an effective add-on in breast cancer related chemo- and radiotherapy. For this reason, imatinib remains a promising drug in the treatment of breast cancer.

\section{Acknowledgements}

This study was supported by an unrestricted grant from Novartis Oncology, Germany. We thank our lab technicians Sigrid Haman and Frank Roesel for their extensive practical contribution and their substantial support.

\section{Author details}

'Department of Obstetrics and Gynecology, Breast Center, University of Kiel, Arnold-Heller Strasse 3, 24105 Kiel, Germany. ${ }^{2}$ Department of Obstetrics and Gynecology, Breast Center, University of Aachen, Germany. ${ }^{3}$ Department of Radiotherapy (Radiooncology), University of Kiel, Germany.

\section{Authors' contributions}

MTW participated in the design of the study, carried out the drug interaction and apoptosis assays, performed the statistical analysis and drafted the manuscript. LD helped carrying out the drug interaction assays. CS participated in the study design. DOB helped drafting the manuscript. $\mathrm{KW}$ carried out the immunoblotting and participated in the irradiation. PN carried out the irradiation and was involved in the study design. MB was involved in the data analysis and helped drafting the manuscript. AS helped to draft the manuscript. WJ was involved in the study design. NM helped to draft the manuscript. CM participated in the study design and its

coordination and helped to draft the manuscript. All authors have read and approved the manuscript.

\section{Competing interests}

We confirm that all authors fulfil all conditions required for authorship. We also confirm that there is no potential conflict of interest or financial dependence regarding this publication, as described in the Instruction for Authors.

Received: 26 January 2010 Accepted: 9 August 2010

Published: 9 August 2010

\section{References}

1. Niehoff $P$, et al: Breast irradiation with brachytherapy: approved techniques and new concepts. Minerva Ginecol 2007, 59(4):377-86.

2. Vlahovic G, Crawford J: Activation of tyrosine kinases in cancer. Oncologist 2003, 8(6):531-8

3. Nahta R, Hortobagyi GN, Esteva FJ: Growth factor receptors in breast cancer: potential for therapeutic intervention. Oncologist 2003, 8(1):5-17.

4. Fong $T A$, et al: SU5416 is a potent and selective inhibitor of the vascular endothelial growth factor receptor (Flk-1/KDR) that inhibits tyrosine kinase catalysis, tumor vascularization, and growth of multiple tumor types. Cancer Res 1999, 59(1):99-106. 
5. Noble ME, Endicott JA, Johnson LN: Protein kinase inhibitors: insights into drug design from structure. Science 2004, 303(5665):1800-5.

6. Clarke $M$, et al: Effects of radiotherapy and of differences in the extent of surgery for early breast cancer on local recurrence and 15-year survival: an overview of the randomised trials. Lancet 2005, 366(9503):2087-106.

7. Bartelink $\mathrm{H}$, et al: Impact of a higher radiation dose on local control and survival in breast-conserving therapy of early breast cancer: 10-year results of the randomized boost versus no boost EORTC 22881-10882 trial. J Clin Oncol 2007, 25(22):3259-65.

8. Baranowska-Kortylewicz J, et al: Effect of platelet-derived growth factor receptor-beta inhibition with STI571 on radioimmunotherapy. Cancer Res 2005, 65(17):7824-31.

9. Mendel DB, et al: In vivo antitumor activity of SU11248, a novel tyrosine kinase inhibitor targeting vascular endothelial growth factor and platelet-derived growth factor receptors: determination of a pharmacokinetic/pharmacodynamic relationship. Clin Cancer Res 2003, 9(1):327-37.

10. Buchdunger $E$, et al: Abl protein-tyrosine kinase inhibitor STI571 inhibits in vitro signal transduction mediated by c-kit and platelet-derived growth factor receptors. J Pharmacol Exp Ther 2000, 295(1):139-45.

11. Druker BJ: Imatinib as a paradigm of targeted therapies. Adv Cancer Res 2004, 91:1-30.

12. Heinrich $M C$, et al: Inhibition of c-kit receptor tyrosine kinase activity by STI 571, a selective tyrosine kinase inhibitor. Blood 2000, 96(3):925-32.

13. Pietras RJ: Interactions between estrogen and growth factor receptors in human breast cancers and the tumor-associated vasculature. Breast $J$ 2003, 9(5):361-73.

14. Attoub S, et al: The c-kit tyrosine kinase inhibitor STI571 for colorectal cancer therapy. Cancer Res 2002, 62(17):4879-83.

15. Antoniades $\mathrm{HN}$, et al: Malignant epithelial cells in primary human lung carcinomas coexpress in vivo platelet-derived growth factor (PDGF) and PDGF receptor mRNAs and their protein products. Proc Natl Acad Sci USA 1992, 89(9):3942-6

16. Fudge K, Bostwick DG, Stearns ME: Platelet-derived growth factor A and B chains and the alpha and beta receptors in prostatic intraepithelial neoplasia. Prostate 1996, 29(5):282-6.

17. Lindmark $G$, et al: Stromal expression of platelet-derived growth factor beta-receptor and platelet-derived growth factor B-chain in colorectal cancer. Lab Invest 1993, 69(6):682-9.

18. Schiffer CA: Signal transduction inhibition: changing paradigms in cancer care. Semin Oncol 2001, 28(5 Suppl 17):34-9.

19. Mundhenke $C$, et al: Novel treatment of ovarian cancer cell lines with Imatinib mesylate combined with Paclitaxel and Carboplatin leads to receptor-mediated antiproliferative effects. J Cancer Res Clin Oncol 2008

20. Lev DC, et al: Inhibition of platelet-derived growth factor receptor signaling restricts the growth of human breast cancer in the bone of nude mice. Clin Cancer Res 2005, 11(1):306-14.

21. de Jong JS, et al: Expression of growth factors, growth inhibiting factors, and their receptors in invasive breast cancer. I: An inventory in search of autocrine and paracrine loops. J Pathol 1998, 184(1):44-52.

22. Ariad S, Seymour L, Bezwoda WR: Platelet-derived growth factor (PDGF) in plasma of breast cancer patients: correlation with stage and rate of progression. Breast Cancer Res Treat 1991, 20(1):11-7.

23. Seymour L, Bezwoda WR: Positive immunostaining for platelet derived growth factor (PDGF) is an adverse prognostic factor in patients with advanced breast cancer. Breast Cancer Res Treat 1994, 32(2):229-33.

24. Heldin $\mathrm{CH}$, Ostman A, Ronnstrand L: Signal transduction via plateletderived growth factor receptors. Biochim Biophys Acta 1998, 1378(1) F79-113.

25. Kennedy SG, et al: The PI 3-kinase/Akt signaling pathway delivers an antiapoptotic signal. Genes Dev 1997, 11(6):701-13.

26. Uehara $H$, et al: Effects of blocking platelet-derived growth factorreceptor signaling in a mouse model of experimental prostate cancer bone metastases. J Natl Cancer Inst 2003, 95(6):458-70.

27. Apte $S M$, et al: Targeting the platelet-derived growth factor receptor in antivascular therapy for human ovarian carcinoma. Clin Cancer Res 2004, 10(3):897-908

28. Langley RR, et al: Activation of the platelet-derived growth factorreceptor enhances survival of murine bone endothelial cells. Cancer Res 2004, 64(11):3727-30.
29. Pietras K, et al: Inhibition of platelet-derived growth factor receptors reduces interstitial hypertension and increases transcapillary transport in tumors. Cancer Res 2001, 61(7):2929-34.

30. Pietras $\mathrm{K}$, et al: Inhibition of PDGF receptor signaling in tumor stroma enhances antitumor effect of chemotherapy. Cancer Res 2002, 62(19):5476-84.

31. Weigel MT, et al: Combination of imatinib and vinorelbine enhances cell growth inhibition in breast cancer cells via PDGFR beta signalling. Cancer Lett 2008

32. Chou TC: Derivation and properties of Michaelis-Menten type and Hill type equations for reference ligands. J Theor Biol 1976, 59(2):253-76.

33. Chou TC, Talalay P: Generalized equations for the analysis of inhibitions of Michaelis-Menten and higher-order kinetic systems with two or more mutually exclusive and nonexclusive inhibitors. Eur J Biochem 1981, 115(1):207-16.

34. Roussidis AE, et al: The importance of c-Kit and PDGF receptors as potential targets for molecular therapy in breast cancer. Curr Med Chem 2007, 14(7):735-43.

35. Carvalho I, et al: Overexpression of platelet-derived growth factor receptor alpha in breast cancer is associated with tumour progression. Breast Cancer Res 2005, 7(5):R788-95.

36. Bhardwaj B, et al: Localization of platelet-derived growth factor beta receptor expression in the periepithelial stroma of human breast carcinoma. Clin Cancer Res 1996, 2(4):773-82.

37. Paulsson J, et al: Prognostic significance of stromal platelet-derived growth factor beta-receptor expression in human breast cancer. Am J Pathol 2009, 175(1):334-41.

38. Jechlinger $M$, et al: Autocrine PDGFR signaling promotes mammary cancer metastasis. J Clin Invest 2006, 116(6):1561-70.

39. Zhu $L$, et al: Possible predictive markers related to micro-metastasis in breast cancer patients. Oncol Rep 2006, 15(5):1217-23.

40. Skinner MA, Safford SD, Freemerman AJ: RET tyrosine kinase and medullary thyroid cells are unaffected by clinical doses of STI571. Anticancer Res 2003, 23(5A):3601-6.

41. Li J, et al: Effects of STI571 (gleevec) on pancreatic cancer cell growth. Mol Cancer 2003, 2(32)

42. Druker BJ, et al: Efficacy and safety of a specific inhibitor of the BCR-ABL tyrosine kinase in chronic myeloid leukemia. N Engl J Med 2001, 344(14):1031-7.

43. Krystal GW, et al: The selective tyrosine kinase inhibitor STI571 inhibits small cell lung cancer growth. Clin Cancer Res 2000, 6(8):3319-26.

44. McHowat J, et al: Clinical concentrations of doxorubicin inhibit activity of myocardial membrane-associated, calcium-independent phospholipase A(2). Cancer Res 2001, 61(10):4024-9.

45. Blagosklonny MV, Fojo T: Molecular effects of paclitaxel: myths and reality (a critical review). Int J Cancer 1999, 83(2):151-6.

46. Yerushalmi $\mathrm{R}$, et al: Combined antiproliferative activity of imatinib mesylate (STI-571) with radiation or cisplatin in vitro. Exp Oncol 2007, 29(2):126-31

47. Katayama R, et al: Imatinib mesylate inhibits platelet-derived growth factor activity and increases chemosensitivity in feline vaccineassociated sarcoma. Cancer Chemother Pharmacol 2004, 54(1):25-33.

48. Modi S, et al: A phase II trial of imatinib mesylate monotherapy in patients with metastatic breast cancer. Breast Cancer Res Treat 2005, 90(2):157-63.

49. Cristofanilli $M$, et al: Imatinib mesylate $(\operatorname{Gleevec}(\mathrm{R}))$ in advanced breast cancer-expressing C-Kit or PDGFR-\{beta\}: clinical activity and biological correlations. Ann Oncol 2008.

50. Yardley DA, et al: Phase II trial of docetaxal plus imatinib mesylate in the treatment of patients with metastatic breast cancer. Clin Breast Cancer 2009, 9(4):237-42.

51. Fertil B, Malaise EP: Intrinsic radiosensitivity of human cell lines is correlated with radioresponsiveness of human tumors: analysis of 101 published survival curves. Int I Radiat Oncol Biol Phys 1985, 11(9):1699-707.

52. Matthews JH, Meeker BE, Chapman JD: Response of human tumor cell lines in vitro to fractionated irradiation. Int J Radiat Oncol Biol Phys 1989, 16(1):133-8.

53. Geng L, et al: STI571 (Gleevec) improves tumor growth delay and survival in irradiated mouse models of glioblastoma. Int I Radiat Oncol Biol Phys 2006, 64(1):263-71. 
54. Servidei T, et al: Increased sensitivity to the platelet-derived growth factor (PDGF) receptor inhibitor STI571 in chemoresistant glioma cells is associated with enhanced PDGF-BB-mediated signaling and STI571induced Akt inactivation. J Cell Physiol 2006, 208(1):220-8.

55. Chung HW, et al: Radiosensitization effect of STI-571 on pancreatic cancer cells in vitro. Int J Radiat Oncol Biol Phys 2009, 75(3):862-9.

56. Russell JS, et al: Gleevec-mediated inhibition of Rad51 expression and enhancement of tumor cell radiosensitivity. Cancer Res 2003, 63(21):7377-83.

57. Holdhoff $M$, et al: Imatinib mesylate radiosensitizes human glioblastoma cells through inhibition of platelet-derived growth factor receptor. Blood Cells Mol Dis 2005, 34(2):181-5.

58. Oertel $\mathrm{S}$, et al: Human glioblastoma and carcinoma xenograft tumors treated by combined radiation and imatinib (Gleevec). Strahlenther Onkol 2006, 182(7):400-7.

59. Pietras K: Increasing tumor uptake of anticancer drugs with imatinib. Semin Oncol 2004, 31(2 Suppl 6):18-23.

60. Matei $\mathrm{D}$, Chang $\mathrm{DD}$, Jeng $\mathrm{MH}$ : Imatinib mesylate (Gleevec) inhibits ovarian cancer cell growth through a mechanism dependent on platelet-derived growth factor receptor alpha and Akt inactivation. Clin Cancer Res 2004, 10(2):681-90.

\section{Pre-publication history}

The pre-publication history for this paper can be accessed here: http://www.biomedcentral.com/1471-2407/10/412/prepub

doi:10.1186/1471-2407-10-412

Cite this article as: Weigel et al: In vitro effects of imatinib mesylate on radiosensitivity and chemosensitivity of breast cancer cells. BMC Cancer 2010 10:412.

\section{Submit your next manuscript to BioMed Central and take full advantage of:}

- Convenient online submission

- Thorough peer review

- No space constraints or color figure charges

- Immediate publication on acceptance

- Inclusion in PubMed, CAS, Scopus and Google Scholar

- Research which is freely available for redistribution

Submit your manuscript at www.biomedcentral.com/submit 